\title{
Early childhood infection and atopic disorder
}

\author{
I Sadaf Farooqi, Julian M Hopkin
}

\begin{abstract}
Background-Atopy is of complex origins but the recent rise in atopic diseases in westernised communities points to the action of important environmental effects. One candidate mechanism is the changing pattern of microbial exposure in childhood. This epidemiological study investigated the relationship between childhood infections and subsequent atopic disease, taking into account a range of social and medical variables.

Methods-A total of 1934 subjects representing a retrospective 1975-84 birth group at a family doctor practice in Oxfordshire were studied. Public health and practice records were reviewed; temporal records were made of all diagnoses of infections and their treatments, all immunisations, and diagnoses of asthma, hay fever and eczema; maternal atopy and a number of other variables were documented.

Results-Logistic regression analysis identified three statistically significant predictors of subsequent atopic disease: maternal atopy $(1.97,95 \%$ CI 1.46 to 2.66 , p<0.0001), immunisation with whole-cell pertussis vaccine $(1.76,95 \%$ CI 1.39 to $2.23, \mathrm{p}<0.0001$ ), and treatment with oral antibiotics in the first two years of life (2.07, 95\% CI 1.64 to $2.60, p<0.0001)$. There was no significant association found for maternal smoking, bottle feeding, sibship size, or social class.

Conclusions-The prediction of atopic disease by maternal atopy mainly reflects the effect of acknowledged genetic factors. Interpretation of the prediction of atopic disorders by immunisation with wholecell pertussis vaccine and treatment with oral antibiotics needs to be very cautious because of the possibilities of confounding effects and reverse causation. However, plausible immune mechanisms are identifiable for the promotion of atopic disorders by both factors and further investigation of these associations is warranted.

(Thorax 1998;53:927-932)
\end{abstract}

Keywords: atopy; infection; genetics

Atopic diseases, characterised by dominant $\mathrm{T}$ helper 2 (Th2) mechanisms and the production of immunoglobulin $\mathrm{E}$ ( $\mathrm{IgE}$ ) to common environmental allergens, are rising in prevalence in westernised communities. ${ }^{12}$ Changes over such a short genetic interval point to important environmental determinants and the changing pattern of infections in such commu- nities is one important candidate mechanism. Recent studies have shown an inverse association between exposure to intracellular infections including tuberculosis, ${ }^{3}$ measles, ${ }^{4}$ and hepatitis $A^{5}$ and atopic disorder. Since many intracellular infections generate predominantly Th1 immune responses, and since Th1 and Th2 immune mechanisms are to a degree mutually antagonistic, ${ }^{6}$ it can be envisaged that exposure to certain infections may repress atopic disorder. Other organisms may directly promote Th2 immune mechanisms. ${ }^{7}$ The observation of an association between smaller sibship size and atopic disorders in population surveys ${ }^{89}$ has led to the "hygiene" hypothesis which suggests that fewer infections amongst smaller sibships might promote atopic responses.

To investigate the putative relationship between childhood infections and atopic disorders further, we conducted a detailed temporal analysis of family doctor recorded diagnoses of childhood infections, including treatments and immunisations, and diagnoses of asthma, hay fever, and eczema for a 1975-84 birth group at a single general practice.

\section{Methods}

SUBJECTS

Of 3062 individuals representing the 1975-84 birth cohort at an Oxfordshire general practice, 1934 had remained registered at the practice throughout their lives and complete data were available on childhood immunisations and updated records of life time health. Excluded from the study were 1125 who had left the practice and three who had died. Data on the 1934 study subjects were collected from the Oxfordshire Child Health database (including formal positive and negative recordings of immunisations on all individuals), maternal delivery records, the general practice database and patient records, which were reviewed by a single observer (ISF). These records are updated weekly and accurately reflect the patient population of the practice during the period of study (August to October 1996).

PRENATAL AND PERINATAL RISK FACTORS

Variables recorded included sex, month and year of birth, birth weight, method of feeding (breast/bottle) at discharge from the obstetric unit, and number of older siblings. A maternal history of atopic disorders (hay fever and asthma) was noted; maternal smoking was recorded as positive if the subject's mother had ever smoked regularly. Social class was defined by paternal occupation.

IMMUNISATIONS

Partial or completed courses of diphtheria, pertussis, tetanus, polio and measles immuni-
7 May 1998

Accepted for publication

25 June 1998 
sations were documented. Only complete immunisation records were included; a negative record signifies vaccine not given rather than not documented. From 1975 to 1984 whole-cell Bordetella pertussis vaccine was administered at three, five, and nine months of age as a triple vaccine with diphtheria and tetanus toxoids and an aluminium hydroxide adjuvant (DPT). Measles vaccine was offered at 13 months of age throughout; from 1992 some female subjects received further measles immunisation in conjunction with rubella vaccine, but the latter were excluded from our analysis. BCG (bacillus Calmette-Guerin) immunisation given at 14 years of age was suspended in Oxfordshire in 1981 and therefore none of this group had received BCG.

\section{CHILDHOOD INFECTIONS}

A detailed search of the medical records was made noting all episodes of infection diagnosed by the family doctor up to the age of 12 years. Specific clinical diagnoses included croup, whooping cough, measles, mumps, and chickenpox (there was no tuberculosis). All other episodes of infection were recorded, noting the clinical diagnosis, the age in months at diagnosis, and antibiotic treatment given. We distinguished the site of infection: otitis media, tonsillitis, upper respiratory tract infection (respiratory symptoms without crepitations), lower respiratory tract infections (respiratory symptoms with crepitations), urinary tract infections, and other infections (mainly skin infections). For respiratory tract infections the presence or absence of wheeze was noted; infections with wheeze were excluded from the analysis for subsequent atopic disorders.

\section{ATOPIC DISORDERS}

A diagnosis of atopic disorder and the age at diagnosis were recorded; atopic disorders were defined by the presence of one or more of infantile eczema (characteristic rash), hay fever (seasonal nasal or ocular irritation), and asthma (recurrent episodes of wheeze after the age of two years). A diagnosis of wheezy bronchitis (wheezing under two years of age) was also noted. Prescriptions for nasal, inhaled or oral corticosteroids, antihistamines, and bronchodilators $\left(\beta_{2}\right.$ agonists) were recorded. The number of visits to the general practitioner in early ( $\leqslant 5$ years) and late childhood (6-12 years) was documented.

STATISTICAL ANALYSIS

Eighty subjects were diagnosed with atopic disorders (all with eczema) before the completion of immunisations or before the diagnosis of certain infections; these subjects were excluded from the analyses for subsequent atopic disorders.

Stepwise logistic regression analysis was performed incorporating all the medical and social variables studied including social class, year of birth, and number of visits to the family doctor in early childhood ( $\mathrm{p}$ for inclusion $<0.2$, $\mathrm{p}$ for exclusion $>0.4$, to include weak effects). All interactions between variables were included in the analysis. A reduced model was produced by backward elimination and subjected to goodness of fit testing. The data were analysed using Stata Statistical Software Release 4.0, 1995 (Statacorp, Texas, USA).

\section{Results}

A total of $879(45.4 \%)$ of the 1975-84 birth group developed symptoms of atopic disorders: asthma, eczema and hay fever were diagnosed in $25 \%, 19 \%$, and $25 \%$, respectively. Asthma and hay fever were diagnosed after the age of 10 years in the majority of subjects $(80 \%$ and $85 \%$, respectively); most children with eczema $(59 \%)$ were diagnosed by the age of two years. There was minimal overlap $(n=8)$ between the diagnosis of wheezy bronchitis ( $\mathrm{n}$ = 135) and asthma $(n=485)$.

PRENATAL AND PERINATAL RISK FACTORS

There was a statistically significant association between maternal atopy and all atopic disorders and between maternal smoking and asthma (table 1). No association was found between low birth weight $(<2500 \mathrm{~g})$, month of birth (data not shown), or bottle milk feeding and any atopic disorder. A similar proportion of subjects in each social class developed atopic disorders (class I, $42 \%$; class II, $43 \%$; class III, $46 \%$; class IV, $39 \%$; class V, $51 \%$ ).

IMMUNISATIONS

Pertussis immunisation

The uptake for DPT immunisation ranged between $54 \%$ and $84 \%$ per year, while the

Table 1 Association with atopy for prenatal and perinatal risk factors, immunisations, and childhood infections

\begin{tabular}{|c|c|c|c|c|c|c|}
\hline & \multicolumn{2}{|c|}{$\%$ atopic (n) if risk factor } & \multirow[b]{2}{*}{ Atopy } & \multicolumn{3}{|c|}{ Unadjusted odds ratios ( $95 \%$ CI) } \\
\hline & Absent & Present & & Asthma & Hay fever & Eczema \\
\hline \multicolumn{7}{|c|}{ Prenatal and perinatal factors } \\
\hline Maternal atopy & $42(1564)$ & $59(369)$ & $1.92(1.52 \text { to } 2.41)^{\star \star \star}$ & $1.94(1.52 \text { to } 2.48)^{\star \star \star}$ & $1.91(1.50 \text { to } 2.44)^{\star \star \star}$ & $1.73(1.33 \text { to } 2.26)^{\star \star \star}$ \\
\hline Maternal smoking & $45(1440)$ & $48(493)$ & $1.16(0.95$ to 1.43$)$ & $1.29(1.03 \text { to } 1.63)^{\star}$ & $1.04(0.82$ to 1.32$)$ & $0.97(0.75$ to 1.26$)$ \\
\hline Low birth weight & 45 (1388) & $51(82)$ & $1.26(0.81$ to 1.96$)$ & $1.00(0.60$ to 1.66$)$ & $0.92(0.55$ to 1.55$)$ & $1.11(0.64$ to 1.94$)$ \\
\hline Bottle feeding & $45(947)$ & $47(506)$ & $1.07(0.86$ to 1.33$)$ & $1.09(0.86$ to 1.40$)$ & $1.08(0.85$ to 1.39$)$ & $1.02(0.77$ to 1.35$)$ \\
\hline \multicolumn{7}{|l|}{ Immunisations } \\
\hline Pertussis & $36(498)$ & $46(1357)$ & $1.57(1.28 \text { to } 1.95)^{\star \star \star}$ & $1.44(1.17 \text { to } 1.85)^{\star \star}$ & $1.56(1.21 \text { to } 2.02)^{\star \star}$ & $1.37(1.12 \text { to } 2.01)^{\star}$ \\
\hline Measles & $40(196)$ & $44(1659)$ & $1.16(0.86$ to 1.57$)$ & $1.13(0.79$ to 1.61$)$ & $1.23(0.86$ to 1.77$)$ & $1.12(0.74$ to 1.68$)$ \\
\hline \multicolumn{7}{|l|}{ Specific infections } \\
\hline Whooping cough & $43(1754)$ & $56(101)$ & $1.73(1.16 \text { to } 2.59)^{\star}$ & $1.83(1.21 \text { to } 2.79)^{\star \star}$ & $1.19(0.76$ to 1.87$)$ & $1.51(0.94$ to 2.44$)$ \\
\hline Measles & $44(1770)$ & $40(85)$ & $0.86(0.55$ to 1.33$)$ & $0.91(0.55$ to 1.53$)$ & $0.93(0.55$ to 1.56$)$ & $0.82(0.44$ to 1.51$)$ \\
\hline Mumps & $41(1492)$ & $54(363)$ & $1.69(1.34 \text { to } 2.13)^{\star \star \star}$ & $1.41(1.10 \text { to } 1.83)^{\star}$ & $1.85(1.44 \text { to } 2.39)^{\star \star \star}$ & $1.43(1.07 \text { to } 1.91)^{\star}$ \\
\hline Croup & $43(1723)$ & $57(132)$ & $1.78(1.24 \text { to } 2.54)^{\star \star}$ & $1.60(1.09 \text { to } 2.33)^{\star}$ & $1.69(1.16 \text { to } 2.46)^{\star}$ & $1.75(1.16 \text { to } 2.64)^{\star}$ \\
\hline Chickenpox & $41(1270)$ & $49(585)$ & $1.41(1.16 \text { to } 1.72)^{\star \star}$ & $1.44(1.15 \text { to } 1.80)^{\star \star}$ & $1.33(1.06 \text { to } 1.66)^{\star}$ & $1.40(1.09 \text { to } 1.81)^{\star}$ \\
\hline Antibiotics $<2$ years & $28(618)$ & $51(1237)$ & $2.62(2.13 \text { to } 3.23)^{\star \star \star \star}$ & $3.19(2.43 \text { to } 4.18)^{\star \star \star \star}$ & $2.04(1.59 \text { to } 2.62)^{\star \star \star}$ & $2.04(1.53 \text { to } 2.73)^{\star \star \star}$ \\
\hline
\end{tabular}

${ }^{\star} \mathrm{p}<0.05 ;{ }^{\star \star} \mathrm{p}<0.005 ;{ }^{\star \star \star} \mathrm{p}<0.0005$ 


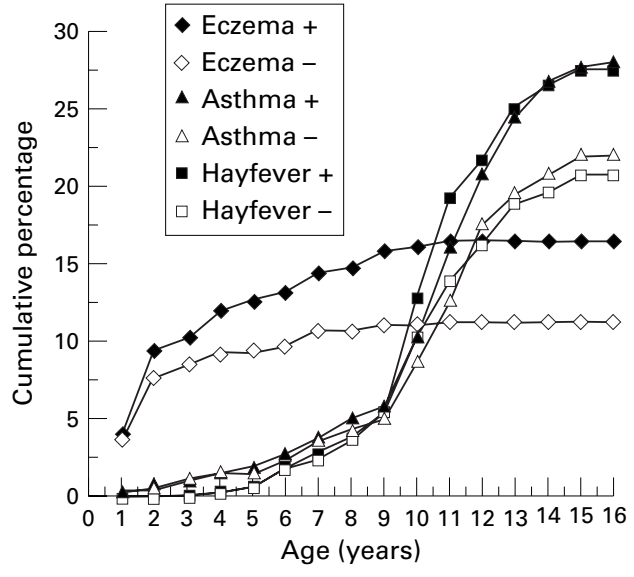

Figure 1 Cumulative atopic diseases (\%) by age with (+) and without (-) pertussis immunisation.

uptake for diphtheria and tetanus immunisation (DT) was almost complete $(>98 \%)$. Five hundred and seventeen subjects $(27 \%)$ did not receive the pertussis component of the triple vaccine, $7 \%$ received an incomplete course of pertussis immunisation, and $66 \%$ received a complete course.

Pertussis immunisation was significantly associated with subsequent atopic disorders whether subjects received an incomplete or complete course (table 1 ). Pertussis immunisation also predicted the use of $\beta_{2}$ agonists (OR $1.53,95 \%$ CI 1.12 to 2.09 , p<0.007), antihistamines (OR 1.58, 95\% CI 1.06 to 2.34 , $\mathrm{p}<0.02$ ), and nasal and inhaled sodium cromoglycate and corticosteroid preparations (OR $1.61,95 \%$ CI 1.19 to 2.19 , p<0.002). It did not significantly predict wheezy bronchitis (OR $1.43,95 \%$ CI 0.93 to $2.19, \mathrm{p}=0.1$ ).

Pertussis vaccine uptake varied during the period studied, but the relationship between pertussis immunisation and atopic disorders did not depend on year of birth or the time of follow up in our group. All subjects were followed up to at least 12 years of age, thereby encompassing the peak incidence of atopic disorders (fig 1). The excess cases of eczema, hay fever and asthma associated with pertussis immunisation occurred at the natural peak age for each disorder.

The number of visits to the family doctor practice in early childhood was very similar in those who received and those who did not receive pertussis immunisation and an adjustment for this was incorporated into the logistic regression model (see below).

CHILDHOOD INFECTIONS

A whole range of specific and non-specific childhood infections, with the exception of measles, was associated with subsequent atopic disorders.

\section{Specific infections}

In a preliminary analysis whooping cough, mumps, and croup were positively associated with subsequent atopic disorders. Maternal atopy predicted more mumps (OR 1.30, 95\% CI 0.99 to $1.71, \mathrm{p}<0.06$ ), croup (OR 1.21, $95 \%$ CI 0.79 to $1.83, \mathrm{p}<0.38)$, and whooping cough $(1.49,0.95$ to $2.33, \mathrm{p}<0.08)$. These relationships could not be further explained by any other variable studied and failed to reach statistical significance in the logistic regression model (see below).

Non-significant trends towards a negative association between measles infection and subsequent atopic disorders were observed. Measles infection predicted less atopic disorder, whereas measles immunisation did not predict atopic disorders (table 1). Those subjects with measles infection who had not received previous measles immunisation had a lower risk of atopic disorders (OR 0.55, 95\% CI 0.25 to $1.26, \mathrm{p}=0.16)$.

\section{Sibship size}

We found no relationship between the number of older siblings and the number of episodes of any infection, nor with antibiotic treatment in the first two years of life (table 2). Having one older sibling was associated with an increased risk of croup (OR 2.95, 95\% CI 1.52 to 5.70,

Table 2 Birth order, specific and non-specific infections in childhood and other risk factors for atopic disease

\begin{tabular}{|c|c|c|c|c|c|}
\hline \multirow{2}{*}{$\begin{array}{l}\text { Risk factors and atopy (expressed as \% or events } 100 \\
\text { subjects) }\end{array}$} & \multicolumn{5}{|c|}{ Birth order (number of older siblings) } \\
\hline & $1(0) n=346$ & $2(1) n=906$ & 3 (2) $n=454$ & 4 (3) $n=101$ & 5 (4) $n=62$ \\
\hline \multicolumn{6}{|c|}{$\begin{array}{l}\text { Non-specifc infections in first } 2 \text { years of life (events } / 100 \\
\text { subjects) }\end{array}$} \\
\hline Otitis media & 30 & 28 & 26 & 50 & 27 \\
\hline Tonsillitis & 39 & 36 & 35 & 35 & 21 \\
\hline URTI & 53 & 57 & 62 & 55 & 65 \\
\hline LRTI & 26 & 24 & 30 & 23 & 22 \\
\hline Urinary & 2 & 2 & 3 & 3 & 3 \\
\hline \multicolumn{6}{|l|}{ Specifc infections (events/100 subjects) } \\
\hline Whooping cough & 6 & 6 & 4 & 5 & 2 \\
\hline Measles & 5 & 5 & 4 & 4 & 3 \\
\hline Mumps & 16 & 20 & 22 & 21 & 16 \\
\hline Croup & 3 & 8 & 9 & 4 & 10 \\
\hline Chickenpox & 29 & 35 & 29 & 33 & 32 \\
\hline \multicolumn{6}{|l|}{ Other risk factors (\%) } \\
\hline Maternal atopy & 13 & 20 & 22 & 23 & 13 \\
\hline Pertussis immunisation & 67 & 74 & 74 & 74 & 67 \\
\hline Antibiotics $<2$ years & 68 & 68 & 70 & 69 & 68 \\
\hline \multicolumn{6}{|l|}{ Atopic disorders (\%) } \\
\hline Atopy & 44 & 44 & 46 & 61 & 44 \\
\hline Asthma & 28 & 24 & 26 & 28 & 28 \\
\hline Hay fever & 23 & 25 & 25 & 30 & 23 \\
\hline Eczema & 16 & 18 & 21 & 32 & 16 \\
\hline
\end{tabular}

URTI = upper respiratory tract infections; LRTI = lower respiratory tract infections. 
Table 3 Unadjusted odds ratios (95\% CI) for infections in the first year of life and subsequent atopy

\begin{tabular}{|c|c|c|c|c|c|c|}
\hline & Otitis media & Tonsillitis & $L R T I$ & URTI & Urinary & Skin \\
\hline No antibiotics & - & - & - & $1.67(1.23 \text { to } 2.27)^{\star \star}$ & - & - \\
\hline Penicillins & $2.25(1.56 \text { to } 3.23)^{\star \star \star}$ & $1.77(1.22 \text { to } 2.56)^{\star \star}$ & $1.33(0.83$ to 2.15$)$ & $1.67(1.16 \text { to } 2.41)^{\star}$ & $3.83(1.45 \text { to } 10.08)^{\star \star}$ & $3.71(1.65 \text { to } 8.33)^{\star \star}$ \\
\hline Cephalosporins & - & $12.79(6.06 \text { to } 26.93)^{\star \star \star}$ & $10.44(2.55 \text { to } \infty)^{\star \star \star}$ & $4.17(1.48 \text { to } 11.78)^{\star \star}$ & $2.87(1.17 \text { to } 7.02)^{\star}$ & $2.08(0.64$ to 6.80$)$ \\
\hline Macrolides & - & $2.50(1.09 \text { to } 5.74)^{\star}$ & $3.65(1.13 \text { to } 11.78)^{\star}$ & $6.26(1.43 \text { to } \infty)^{\star \star \star}$ & $22.96(3.78 \text { to } \infty)^{\star \star \star}$ & $6.26(0.89$ to $\infty)$ \\
\hline
\end{tabular}

${ }^{\star} \mathrm{p}<0.05 ;{ }^{\star \star} \mathrm{p}<0.005 ;{ }^{\star \star \star} \mathrm{p}<0.0005$

$\infty=$ confidence limit not defined.

LRTI = lower respiratory tract infections, URTI = upper respiratory tract infections.

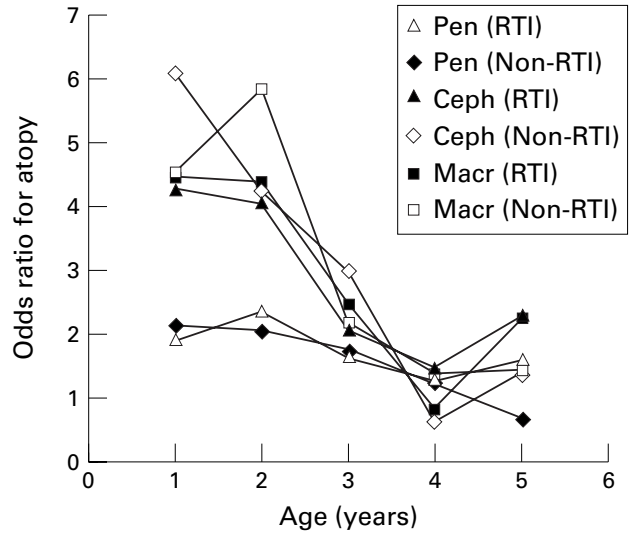

Figure 2 Antibiotic treatments of respiratory tract infections (RTI) and non-RTI in the first five years of life and the subsequent development of atopy. Pen = penicillins; Ceph = cephalosporins; Macr = macrolides.

$\mathrm{p}<0.001)$ and of mumps (OR 1.35, 95\% CI 0.98 to $1.87, \mathrm{p}<0.07)$. There was no association between sibship size and atopic disease.

Non-specific infections and antibiotics

We observed a statistically significant association between a range of infections and subsequent atopic disorders. It was notable that, for infections of the upper respiratory tract, treatment with antibiotics markedly increased the odds ratio for subsequent atopic disorders (table 3). Urinary tract infections treated with an antibiotic were as likely to be associated with subsequent atopic disorders as upper or lower respiratory tract infections without concomitant wheeze. The receipt of an antibiotic in the first two years of life consistently predicted

Table 4 Number of vists to the family doctor in early childhood, antibiotic treatment in the first two years of life, and subsequent atopy

\begin{tabular}{lll}
\hline & \multicolumn{2}{c}{$\%$ subjects with subsequent atopy $(n)$ if } \\
\cline { 2 - 3 } $\begin{array}{l}\text { Number of visits to family doctor in } \begin{array}{l}\text { early childhood (0-5 years) } \\
$\cline { 2 - 3 }\end{array} \\
\text {$forst two years of life }\end{array}$ & $\begin{array}{l}\text { Antibiotic treatment in the } \\
\text { first two years of life }\end{array}$ \\
\hline $0-4$ & $14.8(12 / 81)$ & $47.7(21 / 44)$ \\
$5-9$ & $15.3(21 / 137)$ & $39.6(67 / 169)$ \\
$10-14$ & $31.3(77 / 246)$ & $47.4(263 / 555)$ \\
$15-19$ & $42.6(55 / 129)$ & $56.8(218 / 384)$ \\
$>20$ & $30.0(3 / 10)$ & $71.0(71 / 100)$ \\
\hline
\end{tabular}

Table 5 Rate of subsequent atopy in individuals exposed to more than one independant variable

\begin{tabular}{ll}
\hline Risk factors for atopy & \% atopic $(n)$ \\
\hline None of maternal atopy, pertussis immunisation or antibiotics <2 years & $22(34 / 154)$ \\
Maternal atopy alone & $32(7 / 22)$ \\
Pertussis immunisation alone & $29(106 / 368)$ \\
Antibiotics <2 years alone & $39(100 / 254)$ \\
Maternal atopy and pertussis immunisation & $39(29 / 74)$ \\
Maternal atopy and antibiotics <2 years & $54(36 / 67)$ \\
Pertussis immunisation and antibiotics <2 years & $51(372 / 731)$ \\
Maternal atopy, pertussis immunisation and antibiotics <2 years & $67(124 / 184)$ \\
\hline
\end{tabular}

subsequent asthma, hay fever and eczema (table 1). This association was more marked for infections treated with the broad spectrum antibiotics; no such trend was observed for the weaker association between antibiotic treatment and wheezy bronchitis (OR for penicillin 1.75 , $95 \%$ CI 1.18 to $2.58, \mathrm{p}<0.05)$. Treatment with an antibiotic in early life also predicted the use of $\beta_{2}$ agonists (OR 2.01, 95\% CI 1.66 to $2.44, \mathrm{p}<0.0001$ ), antihistamines (OR $1.42,95 \%$ CI 1.13 to $1.78, \mathrm{p}<0.0024$ ), and nasal (OR $1.71,95 \%$ CI 1.35 to 2.17 , $\mathrm{p}<0.0001$ ) and bronchial disodium cromoglycate and corticosteroid preparations (OR 2.09, $95 \%$ CI 1.61 to $2.70, \mathrm{p}<0.0001$ ).

This association with atopic disorders was principally seen for antibiotic treatment in the first and second year of life (fig 2) and increased with the number of antibiotic courses received (one course, OR $1.85,95 \%$ CI 1.51 to 2.26, p<0.0001; two courses, OR 3.05, 95\% CI 2.14 to $4.34, \mathrm{p}<0.0001$; three courses, OR $8.36,95 \%$ CI 3.26 to $21.41, \mathrm{p}<0.0001)$. Subjects receiving an antibiotic in the first two years made more visits to the family doctor in both early (mean (SD) 16.13 (9.82) versus 11.95 (7.53)) and late childhood (mean (SD) 24.51 (14.49) versus 17.23 (11.22)), but the prediction of atopic disorders by antibiotics was independent of the number of visits to the family doctor (table 4; see logistic regression below). The association between antibiotic treatment in early life and subsequent atopic disorder was similar in those with a history of maternal atopy (OR 1.80, 95\% CI 1.17 to $2.76, p=0.007)$ and those without (OR 2.15, $95 \%$ CI 1.75 to $2.66, \mathrm{p}<0.0001)$.

\section{MULTIPLE LOGISTIC REGRESSION}

Stepwise logistic regression analysis was performed to assess the importance of all variables in predicting atopic disorders and to allow for any confounding effects. From this model, maternal atopy (OR 1.97, 95\% CI 1.46 to 2.66, $\mathrm{p}<0.0001$ ), pertussis immunisation (OR $1.76,95 \%$ CI 1.39 to $2.23, \mathrm{p}<0.0001$ ), and antibiotic treatment in the first two years of life (OR 2.07, 95\% CI 1.64 to $2.60, \mathrm{p}<0.0001$ ) emerged as the only statistically significant predictors of subsequent atopic disorders after correcting for the effects of all the variables studied and their potential interactions, including year of birth and number of visits to the family doctor.

The rate of subsequent atopic disorders in subjects exposed to more than one of these independent variables is shown in table 5 . 


\section{Discussion}

In this retrospective study three variables significantly predicted subsequent asthma, hay fever and eczema-namely, maternal atopy, immunisation with whole-cell pertussis vaccine, and treatment with oral antibiotics in early life. Interpretation of these data needs to take account of the retrospective nature of our study, its methodology based on clinical diagnosis, its confinement to a single general practice, and the limitations these impose on the unravelling of confounding and reverse causation effects.

The diagnostic criteria for asthma, hay fever, and eczema used by the group of 10 family doctors in our study match mainstream diagnostic norms for the UK (see Methods section). The rates of atopic disease are high (asthma 25\%, hay fever $25 \%$, eczema $19 \%$ ) but are not higher than those from other recent estimates in the UK and Europe. ${ }^{11}$ The mean age of diagnosis of asthma and hay fever in our study is later than has been noted in some surveys ${ }^{10}{ }^{11}$; factors contributing to this include the doctor based diagnosis in our study as opposed to subject reported symptoms, and the designation of early life wheezers (under two years of age) as wheezy bronchitis rather than asthma.

The diagnostic methods for infections were based on clinical criteria; our analysis deals with diagnosed infections that were either nonspecific syndromes, such as upper respiratory tract infections, or those that strongly predicted a specific organism such as measles (table 1).

The prediction of childhood atopic disorders by maternal atopy matches earlier observations and mainly reflects the important genetic influences underlying atopic disorders which have been shown to have predominant maternal transmission ${ }^{12-14}$; we did not compare maternal and paternal effects. It remains unclear whether predominant maternal transmission of atopy is due to genomic imprinting or maternal phenotypic modification of the immune system of the developing fetus.

Immunisation with whole cell pertussis vaccine, administered as part of a triple DPT vaccine with alum adjuvant, predicted each of the clinical atopic disorders and their treatments. In considering confounders we noted the following: the prediction occurred when individuals with any atopic disorder prior to immunisation were excluded; those without clinical atopic disease but with a maternal history of atopic disorders were no more or less likely to receive pertussis immunisation; and the prediction was not explained by any of the range of other variables we tested including birth weight, month or year of birth, bottle feeding, maternal smoking, or social class. We considered whether parental choice for pertussis immunisation might also apply to the use of other medical inputs and thus increase the diagnostic rate for atopic disorders, but we found no difference in the number of visits to the doctor between those immunised and those not immunised. We cannot, however, exclude a confounding effect. Association between pertussis immunisation and asthma has been previously reported from a paediatric health survey, ${ }^{15}$ although it was not found in another. ${ }^{16}$ Both studies recorded parent reported symptoms of wheeze in very young children, in contrast to our study which documented doctor diagnosed asthma. In experimental animals a number of observations emphasise the Th2 promoting potential of Bordetella pertussis and its toxins. ${ }^{17}$ It has long been used as an experimental adjuvant for antibody production and in rodents it is a strong promoter of IgE synthesis with an effect on both primary and secondary antibody responses to independent antigens. ${ }^{18} 19$

We found no evidence of fewer infections in general in those developing atopic disease, nor could we relate the rates of doctor diagnosed atopic disorders or infection to sibship size (table 2). The absence of a sibship effect surprised us since it has been noted in a number of previous studies. ${ }^{8920}$ One explanation may be that these studies focused on selfreported symptoms while ours examined doctor diagnosed disorders.

Positive associations were noted between atopic disorders and a range of non-specific infections. Part of the positive association of atopic disorders with non-specific upper and lower respiratory tract infections may be due to more symptomatic infections in atopic individuals, or those predisposed to atopic disorders, or diagnostic overlap. The absence of any microbiological or serological data in our survey limits any comment we can make on the previously reported association between respiratory syncytial virus infection and subsequent asthma. ${ }^{721} \mathrm{~A}$ weak negative association between atopic disorders and measles, which was not statistically significant, matches previous observations in Guinea-Bissau where a history of measles infection predicted fewer allergen skin prick reactions on subsequent testing. ${ }^{4} \mathrm{We}$ found that the odds ratio for clinical atopic disease was lower after clinical measles without preceding measles immunisation (OR 0.55, $95 \%$ CI 0.25 to $1.26, \mathrm{p}=0.16$ ) than after clinical measles with preceding measles immunisation (OR $1.10,95 \%$ CI 0.64 to $1.89, \mathrm{p}=$ $0.72)$. Further information is needed to clarify this issue since measles infection has complex immune effects including downregulation of the Th1 cytokine IL-12 and promotion of the Th2 cytokine IL- 4 in the immediate aftermath of infection. ${ }^{22}$ Our population did not receive BCG vaccination and there were no cases of tuberculosis in the group so we were unable to retest our earlier finding of a strong inverse association between tuberculin responses and atopic disorders in Japanese schoolchildren. ${ }^{3}$

A curious feature of the positive associations between atopic disorders and various infections was the extension to syndromes such as urinary tract infections for which there is no recorded link to atopic disorders. Treatment with antibiotics was common to many of these infective episodes and we noted that antibiotic treatment for upper respiratory tract infections markedly increased the prediction of atopic disorders (table 3 ) and that oral antibiotic treatment for any indication in the first two years of life was the strongest predictor of subsequent atopic disorders within the study. In 
interpreting this, one important issue to consider is reverse causation; since atopic disorders cause respiratory symptoms, which might be confused with or complicated by infection, established atopic disease should predispose to treatment with antibiotics. Furthermore, antibiotics may have been given for infections that might themselves be Th2 promoting such as respiratory syncytial virus. ${ }^{23}$

In a further analysis of the prediction of atopic disorders by treatment with oral antibiotics in early life we noted that removal from the analysis of individuals with diagnosed atopic disease prior to any antibiotic administration showed that antibiotic treatment predicted subsequent atopic disease. Since respiratory atopic disorders evolve with age through childhood, secondary association with antibiotic treatment should strengthen with increasing age but, in fact, we observed that the association with atopic disorders-extending to the peak ages of nine and 10 years for asthma and hay fever-was mainly with antibiotic treatment in the first two years of life (fig 2). The association with antibiotic treatment was significantly higher for asthma (wheeze after the age of two years which relates well to atopic disorders) than for wheezy bronchitis (wheeze under two years which is recognised as a mainly self-limiting non-atopic disorder ${ }^{24}$ ). Those receiving antibiotics had slightly more visits to the doctor (on average one more consultation per year), but this difference had no effect on the prediction of atopic disorders by antibiotics in the logistic regression model. Maternal atopy, an acknowledged and strong predictor of atopic disorders in this and other studies, did not predict antibiotic treatment. We cannot exclude the possibilities of confounders and reverse causation, but these findings raise the possibility of a causal link and the strong prediction of atopic disorders by broad spectrum oral antibiotics (table 3) suggests one plausible mechanism of action which links with experimental data. The microflora of the gut play a crucial role in the programming and development of systemic immunity in early life $^{25} 26$ and animals bred germ-free or those undergoing antibiotic decontamination of the gut display poorly developed lymphoid tissue and impaired Th1 immune mechanisms. ${ }^{27}{ }^{28}$ Thus, treatment of young children with broad spectrum oral antibiotics might also deplete important Th1 promoting elements of the gut microflora at a crucial age leading to Th2 over Th1 immune predominance and increased atopic disorder. Antibiotics may have direct effects on human immune functions. ${ }^{29}$

In summary, our retrospective analysis identifies maternal atopy, pertussis immunisation, and early life treatment with antibiotics as predictors of atopic disorders. The maternal atopy effect is understandable as a genetic effect. Plausible mechanisms for Th2 promotion can be invoked for pertussis immunisation and oral antibiotics, but interpretation of their prediction of atopic disorders in our retrospective study needs to be cautious because confounding and reverse causation effects cannot be excluded. Moreover, both are valuable medical agents and therefore further studies are needed to re-test and clarify these associations.

We would like to thank Dr D Otterburn and his colleagues at The Malthouse Surgery in Abingdon, Oxfordshire for their cooperaMalthouse Surgery in Abingdon, Oxfordshire for their coopera-
tion and access to their family practice patient records, Dr M tion and access to their family practice patient records, Dr M
Goldacre at the Unit of Health Care Epidemiology for making available data from maternal records, Mrs Mary Hetherington from Oxford Child Health for access to immunisation records, $\mathrm{Mr}$ David Smith from the Department of Medical Statistics, Institute of Health Sciences, Oxford for advice, and Dr B Sherry (retired family doctor from Oxford) for illuminating discussions. This work was supported by the Oxford Asthma Research Fund.

1 von Mutius E, Martinez FD, Fritsch C, et al. Prevalence of sthma and atopy in two areas of West and East Germany. Am $\mathcal{F}$ Respir Crit Care Med 1994;149:358-64.

2 Magnus P, Jaakkola JJK. Secular trends in the occurrence of asthma in children and young adults: critical appraisal of repeated cross-sectional surveys. BM7 1997;314:1795-800.

3 Shirakawa T, Enomoto T, Shimazu S, et al. The inverse association between tuberculin responses and atopic disorder. Science 1997;275:77-9.

4 Shaheen SO, Aaby P, Hall AJ, et al. Measles and atopy in Guinea-Bissau. Lancet 1996;347:1792-6.

5 Matricardi PM, Rosmini F, Ferrigno L, et al. Cross-sectional retrospective study of prevalence of atopy among Italian retrospective study of prevalence of atopy among Italian
military students with antibodies against hepatitis A virus. BMflitary students with antiboc

6 Mosmann TR, Sad S. The expanding universe of T-cell Mosmann TR, Sad S. The expanding universe of T-cell
subsets: Th1, Th2 and more. Immunol Today 1996;17:13946.

7 Sigurs N, Bjarnason R, Sigbergsson F, et al. Asthma and immunoglobulin $\mathrm{E}$ after respiratory syncytial virus bronchiolitis: a prospective cohort study with matched controls. Pediatrics 1995;95:500-5.

8 Strachan DP. Hayfever, hygiene and household size. BMF 1989;299:1259-60.

9 von Mutius E, Martinez FD, Fritsch C, et al. Skin test reactivity and number of siblings. BMF 1994;308:692-5.

10 Kaur B, Anderson HR, Austin J, et al. Prevalence of asthma symptoms, diagnosis and treatment in 12-14 year old children across Great Britain (international study of asthma and allergies in childhood, ISAAC UK). BMF 1998;316: $118-24$.

11 Burr ML, Butland BK, King S, et al. Changes in asthma prevalence:two surveys 15 years apart. Arch Dis Child prevalence:two

12 Magnusson CG. Cord serum IgE in relation to family history and as predictor of atopic disease in early infancy. Allergy 1988;43:241-51.

13 Shirakawa T, Airong L, Dubowitz M, et al. Associations between atopy and variants of the beta-subunit of the high affinity immunoglobulin E receptor. Nature Genetics 1994; 7:125-30.

4 Daniels SE, Bhattacharyya S, James A, et al. A genome-wide search for quantitative trait loci underlying asthma. Nature 1996;383:247-50.

15 Odent MR, Culpin EE, Kimmel T. Pertussis vaccination and asthma: is there a link? $\mathcal{F} A M A$ 1994;272:592-3.

16 Nilsson L, Kjellman NIM, Storsaeter J, et al. Lack of association between pertussis vaccination and symptoms of asthma and allergy. $\mathscr{F} A M A$ 1996;275:760.

17 Pauwels R, Van der Straeten M, Platteau B, et al. The nonspecific enhancement of allergy: in vivo effects of Bordetella pertussis vaccine on IgE synthesis. Allergy 1983;38:239-46.

pertussis vaccine on IgE synthesis. Allergy 1983;38:239-46.
18 Mota I, Perini A, Trindade VS. The mechanisms of the adjuvant effect of Bordetella pertussis: the substance respon-
sible for the selective enhancement of IgE antibody production. Int Arch Allergy 1974;47:425.

19 Munoz JJ, Peacock MG. Action of pertussigen (pertussis toxin) on serum IgE and on $\mathrm{Fc}$ epsilon receptors in lymphocytes. Cell Immunol 1990;127:327-36.

20 Strachan DP. Allergy and family size: a riddle worth solving. Clin Exp Allergy 1997;27:235-6.

21 Zach M, Erben A, Olinsky A. Croup, recurrent croup, allergy and airways hyperreactivity. Arch Dis Child 1981;56:336-41.

22 Karp CL, Wysocka M, Wahl, et al. Mechanism of suppression of cell-mediated immunity by measles virus. Science 1996;273:228-31

23 Welliver RC, Duffy L. The relationship of RSV specific immunoglobulin IgE antibody responses in infancy, recurrent wheezing and pulmonary function at 7-8 years. Pediatr Pulmonol 1993;15:19-27.

24 Martinez FD, Wright AL, Taussig LM, et al. Asthma and wheezing in the first six years of life. $N$ Engl $₹$ Med wheezing in the

25 Berg RD. The indigenous gastrointestinal microflora. Trends Microb 1996;4:430-5.

26 Wallace FJ, Cripps AW, Clancy RL, et al. A role for intestinal T lymphocytes in bronchus mucosal immunity. Immunity 1991;74:68-73.

27 MacDonald TT, Carter PB. Requirements for a bacterial flora before mice generate cells capable of mediating delayed hypersensitivity to sheep red blood cells. F Immunol 1979;122:2624-9.

28 Pulverer G, Ko HL, Beuth J. Immunomodulating effects of antibiotics influencing digestive flora. Pathol Biol Paris 1993;41:753-8.

29 van-Vlem B, Vanholder R, De Paepe P, Vogelaers D, Ringoir $\mathrm{S}$. Immunomodulatory effects of antibiotics. Infection 1996;24:275-91. 